\title{
ANNOUNCEMENT
}

\section{European Political Science Prize}

https://doi.org/10.1057/s41304-017-0134-7

W

e are delighted to announce that the European Political Science Annual Prize for 2017 (Volume 16) has been awarded to a Teaching and Training article 'Using dating as an analogy to teach IR theory' by Christopher Pallas and Charity Bucher that was published in Vol 16, Issue 1. The prize-winning article is now free to access.

The judges said 'This is an innovative and novel way to encourage political science students to think about and engage with IR theory. We liked the presentation of the method in a 'recipe- style' so that people can actually apply it, and the discussion is still fulfilling high standards; and the experience of dating is (somewhat) universal so that students from different gendered, social and ethnic backgrounds can relate to it'.

The prize committee was comprised of Professors:

Gabriele Abels, University of Tubingen, Germany

the late Jacqui Briggs, University of Lincoln, UK

Heather Savigny, De Montfort University, UK 